\title{
Interleukin-28B genotypes determine response to pegylated-interferon plus ribavirin therapy in patients with hepatitis $C$ virus infection
}

\author{
RIE OSAKI $^{1}$, TAKASHI NISHIMURA ${ }^{1}$, MAKOTO SHIOYA ${ }^{1}$, TAKAYUKI TAKEUCHI ${ }^{2}$, YOSHIAKI OKUMURA $^{3}$, \\ TAMIO NAKAHARA ${ }^{2}$, SHIGEKI BAMBA ${ }^{1}$, SHINOBU NAKAJO $^{2}$, YOSHIHIDE FUJIYAMA ${ }^{1}$ and AKIRA ANDOH $^{4}$ \\ ${ }^{1}$ Department of Medicine, Shiga University of Medical Science, Seta Tukinowa, Otsu; \\ ${ }^{2}$ Department of Medicine, Notogawa Hospital, Higashioumi; ${ }^{3}$ Department of Medicine, Social \\ Insurance Shiga Hospital, Fujimidai, Otsu; ${ }^{4}$ Division of Mucosal Immunology, Graduate School, \\ Shiga University of Medical Science, Seta Tukinowa, Otsu, Shiga, Japan
}

Received August 14, 2011; Accepted October 26, 2011

DOI: $10.3892 / \mathrm{mmr} .2011 .655$

\begin{abstract}
We recently reported that the interleukin (IL)28B major genotype is a predictor of early suppression of the hepatitis $\mathrm{C}$ virus (HCV) at 12 weeks in response to pegylated interferon (PEG-IFN) plus ribavirin (RBV) therapy. The present study investigated the relationship between IL-28 genotypes and the virological response to PEG-IFN/ RBV therapy at 24 and 48 weeks. Genotypes of the $I L-28 B$ rs8099917 $\mathrm{T}>\mathrm{G}$ single nucleotide polymorphism were determined in 177 patients with HCV infection. Among them, 56 patients with HCV1 infection were treated with PEG-IFN/ RBV. The frequency of the IL-28B major allele (TT) was $73.8 \%$ in patients with HCV serotype 1 and $86.3 \%$ in patients with HCV serotype 2. The rate of HCV-RNA positivity was significantly lower at 48 weeks in patients with the IL-28B major allele compared to patients with the IL-28B minor allele (TG or GG). The rate of HCV-RNA positivity at 24 weeks tended to be lower in patients with the IL-28B major allele, but there was no statistical significance $(\mathrm{P}=0.059)$. The sustained virological response (SVR) rate was $45.9 \%$ in patients with the IL-28B major allele, but $13.3 \%$ in patients with the IL-28B minor allele. The SVR correlated with the IL-28B major allele $(\mathrm{OR}=7.13, \mathrm{P}=0.010)$, early virological response $(\mathrm{OR}=33.3$, $\mathrm{P}=0.008), \mathrm{HCV}-\mathrm{RNA} \leq 6.3 \mathrm{log} \mathrm{IU} / \mathrm{ml}(\mathrm{OR}=81.2, \mathrm{P}=0.009)$ and $\gamma$-GTP $\leq 47 \mathrm{IU} / 1(\mathrm{OR}=49.4, \mathrm{P}=0.027)$. The IL-28B genotype is a significant pre-treatment predictor of the response to PEG-IFN/RBV therapy at 48 weeks in patients with $\mathrm{HCV}$ infection.
\end{abstract}

Correspondence to: Dr Akira Andoh, Division of Mucosal Immunology, Graduate School, Shiga University of Medical Science, Seta Tsukinowa, Otsu, Shiga 520-2192, Japan

E-mail: andoh@belle.shiga-med.ac.jp

Key words: hepatitis C, interferon, interleukin-28

\section{Introduction}

One hundred and eighty million individuals worldwide are chronically infected with the hepatitis $\mathrm{C}$ virus (HCV) 1 and are at risk for related morbidity and mortality from cirrhosis and hepatocellular carcinoma (HCC) (1-4). Since curative antiviral therapy may prevent these complications $(5,6)$, antiviral therapy plays a crucial role in the management of $\mathrm{HCV}$-infected patients. Currently, pegylated interferon (PEG-IFN) plus ribavirin (RBV) is considered to be the most effective standard of treatment for chronic hepatitis $C(2,3,7)$, but the rate of sustained virological response (SVR; HCV RNA negative for 24 weeks after the cessation of therapy) is approximately $50 \%$ in patients with HCV genotype 1. Furthermore, 20-30\% of HCV genotype 1 patients are non-responders to PEG-IFN/ RBV therapy (5).

The most reliable method for predicting the response to PEG-IFN/RBV therapy is to monitor the early decline of serum HCV-RNA levels during treatment $(5,8)$, but there is no established method for prediction before treatment. Since PEG-IFN/RBV therapy is costly when used for an extensive period of time to achieve SVR and as it is often accompanied by adverse effects, such as flu-like symptoms, depression and hematological abnormalities, pre-treatment predictions would be clinically valuable (5). The outcome of IFN therapy has been reported to be associated with both viral and host factors. Representative viral factors are the HCV genotype, high HCV RNA titers (9), amino acid substitutions in the NS5A (10) and core region (11). The host factors include age, body mass index, insulin resistance and stage of liver fibrosis $(6,12)$. Furthermore, a single nucleotide polymorphism (SNP) of the host gene IL-28B is reported to be significantly associated with the response to PEG-IFN/RBV therapy (13-15). A genome-wide association study of the genetic determinants of a therapeutic response in HCV1 patients treated with PEG-IFN/ RBV identified an SNP upstream of the IL-28B gene on chromosome 19, which leads to an approximately 2-fold difference in SVR rates in patients of European, African-American or Hispanic descent (14). 
We recently demonstrated a significant association of the IL-28B major genotype (TT) with early virological response (EVR) to PEG-IFN/RBV therapy at 12 weeks in Japanese patients with HCV infection (16). In this study, we investigated the relationship between the IL-28 genotype and virological response at later periods, at 24 and 48 weeks.

\section{Patients and methods}

Study populations. A total of 177 patients with chronic HCV infection (HCV serotype 1, n=126 and serotype 2, n=51), who were treated at the Hospital of Shiga University of Medical Science, the Notogawa Hospital and the Social Insurance Shiga Hospital were included in the study. Among them, 52 HCV1 patients were treated with PEG-IFN/RBV therapy. Table I lists the demographic features of the patients. The patients received weekly injections of PEG-IFN $\alpha 2 \mathrm{~b}$ at $1.5 \mu \mathrm{g} / \mathrm{kg}$ body weight or PEG-IFN $\alpha 2 \mathrm{~b}$ at 180 or $90 \mu \mathrm{g}$, and oral administration of RBV for 48 weeks. The amount of RBV was adjusted based on the subject's body weight (600 mg for $<60 \mathrm{~kg}, 800 \mathrm{mg}$ for $60-80$ $\mathrm{kg}, 1,000 \mathrm{mg}$ for $>80 \mathrm{~kg}$ ). Only patients with $>75 \%$ compliance with the prescribed doses of PEG-IFN/RBV were included in this study. Informed consent was obtained from all patients. The ethics committee of each participating medical center approved this study.

Serotyping. Serotyping was performed by an enzyme immunoassay-based Murex assay (Murex Diagnostics Inc., Norcross, GA, USA).

Genotyping. The samples were genotyped for $I L-28 B$ rs8099917 using the TaqMan ${ }^{\circledR}$ SNP Assays (Applied Biosystems Inc., Foster City, CA, USA), as previously described (17). Homozygosity (GG) or heterozygosity (TG) of the minor sequence was defined as having the IL-28B minor allele, whereas homozygosity for the major sequence (TT) was defined as having the IL-28B major allele. The HCV RNA levels were analyzed using the TaqMan RT-PCR test. The measurement ranges of these assays were 1.2-7.8 log IU.

Statistical analysis. Hardy-Weinberg equilibrium (HWE) analysis was performed on these subjects by comparing the detected distribution of allele frequencies to the theoretical distribution estimated from the SNP allelic frequencies. P>0.05 (Chi-square statistics) was considered to indicate equilibrium. The categorical variables were presented as frequencies and percentages when needed. The continuous variables were reported as the means $\pm \mathrm{SD}$ (range). The virological kinetics were assessed using the Chi-square test. Multivariate logistic regression analysis with stepwise forward selection was performed with a criterion of $\mathrm{P}<0.05$ for the inclusion or removal of variables. All statistical analysis used the Ekuseru-Toukei 2008 software (Social Survey Research Information Co., Ltd., Tokyo, Japan). P-value of $<0.05$ was considered to denote statistical significance.

\section{Results}

The genotype frequencies of the IL-28B polymorphisms in patients with HCV serotypes 1 and 2 are shown in Table II. The frequency of the IL-28B major allele, defined as homo-
Table I. Baseline characteristics of the patients who were treated with PEG-IFN/RBV therapy.

\begin{tabular}{lc}
\hline No. of patients & 52 \\
Gender (male/female) & $32 / 20$ \\
Age (years) & $62.0 \pm 10.5(38-76)$ \\
Body mass index $\left(\mathrm{kg} / \mathrm{m}^{2}\right)$ & $22.3 \pm 2.8(17.0-30.1)$ \\
Platelet $\left(10^{6} / \mu \mathrm{l}\right)$ & $15.5 \pm 5.2(3.9-29.9)$ \\
ALT $(\mathrm{IU} / \mathrm{l})$ & $58.0 \pm 44.8(21-259)$ \\
$\gamma$-GTP $(\mathrm{IU} / \mathrm{ml})$ & $47.0 \pm 42.0(9-204)$ \\
Albumin $(\mathrm{g} / \mathrm{ml})$ & $4.2 \pm 0.4(3.0-4.8)$ \\
HCV-RNA level $(\log \mathrm{IU} / \mathrm{ml})$ & $6.5 \pm 0.7(4.3-9.0)$ \\
\hline
\end{tabular}

ALT, alanine aminotransferase; GTP, glutamyltransferase. Data are presented as the means $\pm \mathrm{SD}$ (range).

Table II. Genotype distribution of IL-28B SNP rs8099917.

\begin{tabular}{lccccc}
\hline & \multicolumn{5}{c}{ rs8099917 } \\
\cline { 2 - 6 } & TT (\%) & TG (\%) & GG (\%) & T (\%) & G (\%) \\
\hline HCV serotype 1 & 93 & 32 & 1 & - & - \\
& $(73.8)$ & $(25.4)$ & $(0.79)$ & $(86.5)$ & $(13.5)$ \\
HCV serotype 2 & 44 & 7 & 0 & - & - \\
& $(86.3)$ & $(21.7)$ & $(0.00)$ & $(93.1)$ & $(6.7)$ \\
Total & 137 & 39 & 1 & & \\
& $(77.4)$ & $(22.0)$ & $(0.56)$ & $(89.8)$ & $(11.6)$ \\
\hline
\end{tabular}

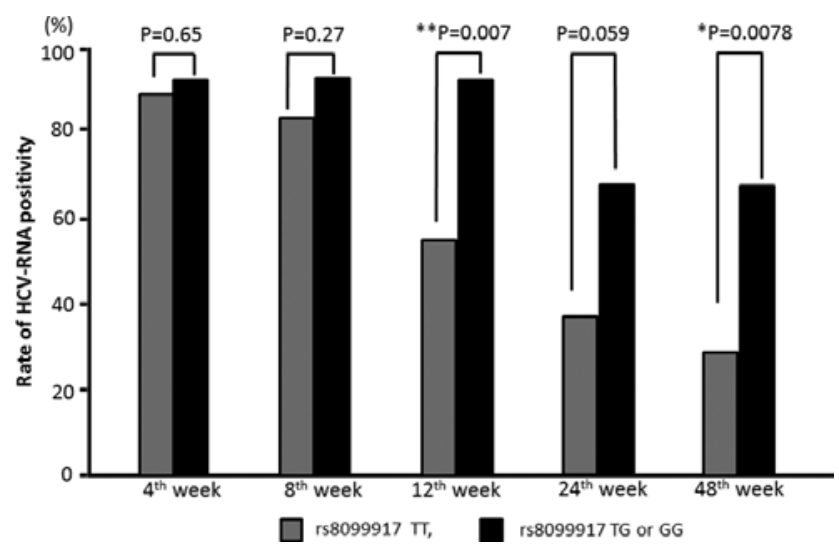

Figure 1. Sequential virological response of the HCV genotype 1 to pegylated interferon (PEG-IFN) plus ribavirin (RBV). Patients with HCV genotype 1 were stratified according to their IL-28B allele type, and the virological responses of HCV-RNA at weeks 4, 8, 12, 24 and 48 following the start of PEG-IFN/RBV therapy were analyzed. ${ }^{*} \mathrm{P}<0.05,{ }^{* * *} \mathrm{P}<0.01$.

zygosity for the major sequence (TT), in HCV serotype 1 patients $(73.8 \%)$ was lower than that of serotype $2(86.3 \%)$ (not significant). The frequency of the rs8099917 $\mathrm{T}$ allele was $86.5 \%$ in the patients with serotype 1 , and $93.1 \%$ in patients with serotype 2 . These data are compatible with a recent report of the Japanese population described by Ochi et al (2).

The patients with HCV genotype 1 were stratified according to their IL-28B allele type; the virological responses 


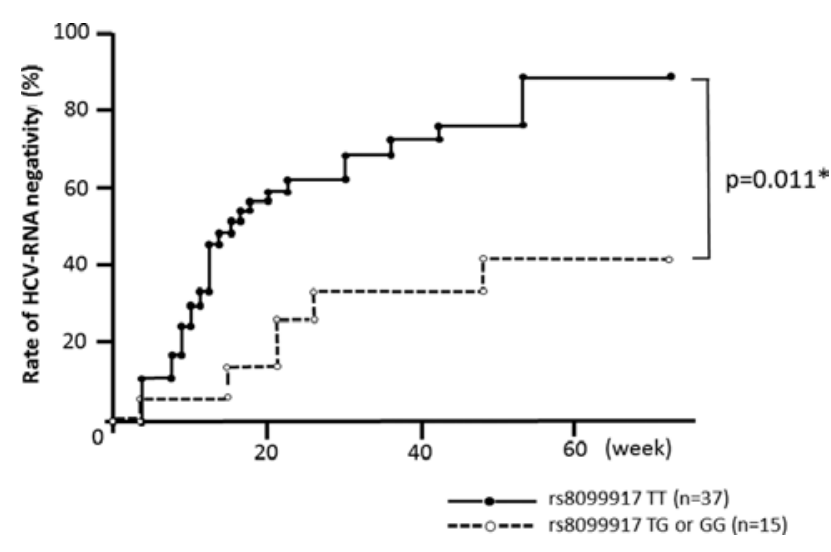

Figure 2. Kaplan-Meier analysis of the rate of viral negativity. Patients with the HCV genotype 1 were stratified according to their IL-28B allele type, and the rate of viral negativity was analyzed.

Table III. Multivariate analyses of factors associated with SVR.

\begin{tabular}{lccc}
\hline & OR & $95 \%$ CI & P-value \\
\hline rs8099917 major allele & 7.13 & $4.79-999$ & $0.010^{\mathrm{a}}$ \\
EVR & 33.3 & $2.53-439$ & $0.008^{\mathrm{b}}$ \\
HCV-RNA $(\leq 6.3 \log \mathrm{IU} / \mathrm{ml})$ & 81.2 & $3.03-999$ & $0.009^{\mathrm{b}}$ \\
$\gamma$-GTP $(\leq 47 \mathrm{IU} / \mathrm{l})$ & 49.4 & $1.54-999$ & $0.027^{\mathrm{a}}$ \\
ALT $(<30 \mathrm{IU} / \mathrm{l})$ & 0.99 & $0.96-1.03$ & 0.087 \\
Platelet $(/ \mu \mathrm{l})$ & 1.43 & $0.97-2.12$ & 0.135 \\
\hline
\end{tabular}

EVR, early virological response at 12 weeks; GTP, glutamyltransferase; ALT, alanine aminotransferase. ${ }^{\mathrm{a}} \mathrm{P}<0.05$; ${ }^{\mathrm{b}} \mathrm{P}<0.01$.

of HCV-RNA at weeks 4, 8, 12, 24 and 48 following the start of PEG-IFN/RBV therapy were analyzed (Fig. 1). The rate of HCV-RNA positivity was significantly lower at 12 and 48 weeks in patients with the IL-28B major allele than in patients with the IL-28B minor allele. The rate of HCV-RNA positivity at 24 weeks tended to be lower in patients with the IL-28B major allele, but there was no statistical significance $(\mathrm{P}=0.059)$. The Kaplan-Meier method revealed that the rate of HCV-RNA negativity was significantly higher in patients with the IL-28B major allele than in patients with the IL-28B minor allele (Fig. 2). These findings suggest that IL-28B has a great impact on the virological response to therapy at later periods (at 48 weeks), compared to our previous report (16).

The SVR rate was $45.9 \%$ in patients with the IL-28B major allele, but $13.3 \%$ in patients with the IL-28B minor allele. The SVR correlated with the IL-28B major allele (OR=7.13, $\mathrm{P}=0.010)$, EVR $(\mathrm{OR}=33.3, \mathrm{P}=0.008), \mathrm{HCV}-\mathrm{RNA} \leq 6.3 \log \mathrm{IU} /$ $\mathrm{ml}(\mathrm{OR}=81.2, \mathrm{P}=0.009)$ and $\gamma-\mathrm{GTP} \leq 47 \mathrm{IU} / \mathrm{l}(\mathrm{OR}=49.4$, $\mathrm{P}=0.027$ ) (Table III).

We compared the effects of PEG-IFN $\alpha-2 a$ and $2 b$, but no significant difference was detected (Fig. 3).

\section{Discussion}

HCV infection is the leading cause of cirrhosis and HCC worldwide (18). The successful eradication of $\mathrm{HCV}$, defined as SVR, is associated with a reduced risk of developing HCC.

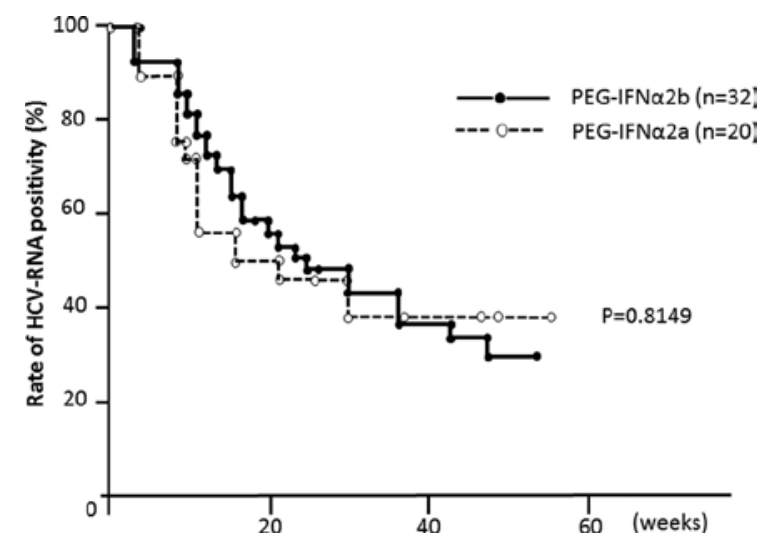

Figure 3. Comparison of the effects of PEG-INF $\alpha-2 a$ and $2 b$ on HCV positivity. Data were analyzed by the Kaplan-Meier method. There were no significant differences between the effects of the two PEG-IFN $\alpha$ formulations.

Currently, PEG-IFN/RBV is the most effective standard of care for patients with chronic hepatitis $\mathrm{C}$, but the rate of SVR is approximately $50 \%$ and the rate of a null virological response is $20-30 \%$ in patients with HCV genotype 1, the most common genotype in Japan, Europe, the US and many other countries $(5,19)$. Furthermore, PEG-IFN/RBV therapy is associated with considerable toxicity. Therefore, a pre-treatment prediction of the patient response to therapy would be of great clinical benefit. However, there have been no reliable baseline predictors for the response to antivirological therapy. We recently reported a significant association between early virological response at 12 weeks and the IL-28B major allele. In the present study, we further investigated whether the IL-28B genotypes can be used as a treatment predictor of a virological response to PEG-IFN/ RBV therapy at weeks 24 and 48.

This study demonstrated that the IL-28B genotype correlated with virological clearance at weeks 24 and 48, as well as at 12 weeks, as described in our recent report (16). The key marker for an improved treatment response was the IL-28B major allele (TT type). The major allele type was associated with improved viral suppression, such that by weeks 24 and 48 , the reduction in virological positivity had doubled in patients with the TT allele as compared to the non-TT IL-28B type HCV1 patients. Thus, the genotyping of IL-28B prior to PEG-IFN/RBV therapy is a useful baseline predictor of virological response which could be used for selecting the treatment regimen: whether to treat patients with PEG-IFN/ RBV or to wait for more effective future therapy, including direct acting antivirological drugs. The patients with the major allele IL-28B have a greater possibility of achieving virological reduction, and should be considered ideal candidates. By contrast, patients with the minor allele (TG or GG type) are unlikely to achieve a satisfactory virological response, and need to be treated with a stronger drug, such as a antivirological protease inhibitor. On the other hand, it remains unclear whether the IL-28B genotype is useful for the prediction of treatment duration and relapse. Previously, Kurosaki et al suggested that the IL-28 genotype may not be suitable for determining the treatment duration and relapse in patients who started PEG-IFN/RBV therapy (5). Whether the IL-28B genotype is useful for prediction of treatment duration and relapse or not merits further investigation. 
The SVR rate was $45.9 \%$ in patients with the IL-28B major allele in the present study, and this was compatible with previous reports $(7,15)$. However, the SVR rate in patients with the IL-28B minor allele was $13.3 \%$, while it was $23 \%$ in Caucasians and $9 \%$ in African-Americans in a study by McCarthy et al (20). The SVR rate in patients having the IL-28B minor allele was $28 \%$ in genotypes $1 / 4$ compared to $80 \%$ in genotypes $2 / 3$ in a study by Rauch et al (21). These data imply that the impact of the IL-28B polymorphism in response to therapy may differ, according to race, geographical area or HCV genotypes.

Several factors have been reported to predict treatment response to PEG-IFN/RBV. In this study, we observed three significant predictors of response independent of IL-28B genotype: early virological response at 12 weeks, viral loads less than $600,000 \mathrm{IU} / \mathrm{ml}$ and normal $\gamma$-GTP. These are supported, in part, by previous reports (22). We recently found that platelet count is another significant predictor of response independent of IL-28B genotype (16), and a similar observation was reported by Rauch et al (21). Since platelet numbers decrease depending on the progress of liver fibrosis (12), PEG-IFN/RBV is more effective for patients with better histological changes of the liver. However, although this study of SVR at the end-of-treatment did not detect such an association, further investigations in a larger number of patients should be undertaken in the future.

Recent direct comparative trials, retrospective and meta-analysis studies have demonstrated that treatment with PEG-IFN $\alpha-2 \mathrm{a}$ is a significant and independent contributor to SVR in patients infected with genotype 1 (23), as compared to treatment with PEG-IFN $\alpha-2 b$, although the largest headto-head trial (IDEAL study) failed to detect a significant difference in SVR rates between these two peg-IFN $\alpha$ formulations (24). Our preliminary analysis also demonstrated that there are no differences in the early virological response between these two PEG-IFN $\alpha$ subtypes.

In conclusion, an IL-28B genotype is the strongest baseline predictor of an early virological response to PEG-IFN/ RBV therapy in HCV1 patients. It is likely that IL-28B SNP genotyping will become part of the clinical assessment before standard antiviral therapy in individuals chronically infected with HCV1. Furthermore, IL-28B encodes a protein known as IFNl $\lambda 3$, which is thought to suppress the replication of various viruses, including HCV (25). The results of the current study may provide a rationale for developing diagnostic testing and a therapeutic approach for targeting IL-28B in chronic hepatitis $\mathrm{C}$ in the future.

\section{Acknowledgements}

This study was supported by MSD Co., Ltd., Tokyo, Japan.

\section{References}

1. Thompson AJ, Muir AJ, Sulkowski MS, et al: Interleukin-28B polymorphism improves viral kinetics and is the strongest pretreatment predictor of sustained virologic response in genotype 1 hepatitis C virus. Gastroenterology 139: 120-129; $\mathrm{e} 118,2010$.

2. Ochi H, Maekawa T, Abe H, et al: IL-28B predicts response to chronic hepatitis $\mathrm{C}$ therapy - fine-mapping and replication study in Asian populations. J Gen Virol 92: 1071-1081, 2011.

3. Hadziyannis SJ and Koskinas JS: Differences in epidemiology, liver disease and treatment response among HCV genotypes. Hepatol Res 29: 129-135, 2004.
4. Michitaka K, Nishiguchi S, Aoyagi Y, Hiasa Y, Tokumoto Y and Onji M: Etiology of liver cirrhosis in Japan: a nationwide survey. J Gastroenterol 45: 86-94, 2010.

5. Kurosaki M, Tanaka Y, Nishida N, et al: Pre-treatment prediction of response to pegylated-interferon plus ribavirin for chronic hepatitis C using genetic polymorphism in IL28B and viral factors. J Hepatol 54: 439-448, 2011.

6. Yasui K, Harano Y, Mitsuyoshi H, et al: Steatosis and hepatic expression of genes regulating lipid metabolism in Japanese patients infected with hepatitis C virus. J Gastroenterol 45: 95-104, 2010.

7. Hadziyannis SJ, Sette H Jr, Morgan TR, et al: Peginterferonalpha2a and ribavirin combination therapy in chronic hepatitis $\mathrm{C}$ : a randomized study of treatment duration and ribavirin dose. Ann Intern Med 140: 346-355, 2004.

8. Nakagawa M, Sakamoto N, Ueyama M, et al: Mutations in the interferon sensitivity determining region and virological response to combination therapy with pegylated-interferon alpha $2 \mathrm{~b}$ plus ribavirin in patients with chronic hepatitis $\mathrm{C}-1 \mathrm{~b}$ infection. J Gastroenterol 45: 656-665, 2010.

9. Iino S, Ichida F, Sakuma A and Suzuki H: A randomized clinical trial with natural interferon-alpha monotherapy for 24 or 48 weeks on patients with chronic hepatitis $C$ having genotype $1 \mathrm{~b}$ infection in high viral titers. Hepatol Res 24: 338-345, 2002.

10. Enomoto N, Sakuma I, Asahina Y, et al: Mutations in the nonstructural protein $5 \mathrm{~A}$ gene and response to interferon in patients with chronic hepatitis $\mathrm{C}$ virus $1 \mathrm{~b}$ infection. $\mathrm{N}$ Engl J Med 334: 77-81, 1996.

11. Akuta N, Suzuki F, Kawamura Y, et al: Predictors of viral kinetics to peginterferon plus ribavirin combination therapy in Japanese patients infected with hepatitis $C$ virus genotype $1 b$. J Med Virol 79: 1686-1695, 2007.

12. Izumi N, Asahina Y and Kurosaki M: Predictors of virological response to a combination therapy with pegylated interferon plus ribavirin including virus and host factors. Hepat Res Treat 2010: $703602,2010$.

13. Tanaka Y, Nishida N, Sugiyama M, et al: Genome-wide association of IL28B with response to pegylated interferon-alpha and ribavirin therapy for chronic hepatitis C. Nat Genet 41: 1105-1109, 2009.

14. Ge D, Fellay J, Thompson AJ, et al: Genetic variation in IL28B predicts hepatitis C treatment-induced viral clearance. Nature 461: 399-401, 2009.

15. Ahlenstiel G, Booth DR and George J: IL28B in hepatitis C virus infection: translating pharmacogenomics into clinical practice. J Gastroenterol 45: 903-910, 2010.

16. Osaki R, Nishimura T, Takeuchi T, et al: Interleukin-28 polymorphisms are associated with an early viral response in patients receiving hepatitis C therapy. Exp Ther Med 2: 715-718, 2011.

17. Livak KJ: Allelic discrimination using fluorogenic probes and the 5' nuclease assay. Genet Anal 14: 143-149, 1999.

18. Ray Kim W: Global epidemiology and burden of hepatitis C. Microbes Infect 4: 1219-1225, 2002.

19. Akuta N, Suzuki F, Sezaki H, et al: Association of amino acid substitution pattern in core protein of hepatitis $C$ virus genotype $1 \mathrm{~b}$ high viral load and non-virological response to interferon-ribavirin combination therapy. Intervirology 48: 372-380, 2005.

20. McCarthy JJ, Li JH, Thompson A, et al: Replicated association between an $I L 28 B$ gene variant and a sustained response to pegylated interferonand ribavirin. Gastroenterology 138: 23072314, 2010.

21. Rauch A, Kutalik Z, Descombes P, et al: Genetic variation in IL28B is associated with chronic hepatitis C and treatmeant failure - a genome-wide association study. Gastroenterology 138: 1338-1345, 2010.

22. Yu ML, Dai CY, Huang JF and Chuang WL: Rapid virological response to peginterferon and ribavirin for hepatitis $\mathrm{C}$ genotype 1: the role of weight-based ribavirin exposure. Hepatology 48: 1019-1020, 2008.

23. Tsubota A, Fujise K, Namiki Y and Tada N: Peginterferon and ribavirin treatment for hepatitis $\mathrm{C}$ virus infection. World $\mathrm{J}$ Gastroenterol 17: 419-432, 2011.

24. McHutchison JG, Lawitz EJ, Shiffman ML, et al: Peginterferon alfa-2b or alfa-2a with ribavirin for treatment of hepatitis $C$ infection. N Engl J Med 361: 580-593, 2009.

25. Marcello T, Grakoui A, Barba-Spaeth G, et al: Interferons alpha and lambda inhibit hepatitis $C$ virus replication with distinct signal transduction and gene regulation kinetics. Gastroenterology 131: $1887-1898,2006$ 